\title{
Social and Political Trust in a Low Trust Society
}

\section{Matías Bargsted $^{1}$ (D) $\cdot$ Camila Ortiz $^{1}$ (I) $\cdot$ Ignacio Cáceres $^{1} \cdot$ Nicolás M. Somma $^{1}$ (iD}

Accepted: 27 November 2021

(c) The Author(s), under exclusive licence to Springer Science+Business Media, LLC, part of Springer Nature 2021

\begin{abstract}
We study the causal relationship between social and political trust in a low trust society, a setting where this topic has received very little attention. We focus on contemporary Chile, a relatively consolidated new democracy lacking many of the conditions that fosters trust such as high socioeconomic equality, weak social divisions, or universal welfare policies. Our empirical analysis is based on a 4-wave panel survey applied to a representative sample of 2000 Chilean adults interviewed face to face each year between 2016 and 2019. Based on statistical models with varying specifications and assumptions, we find support for the institutionalist view that claims that political trust exercises a positive influence over social trust. However, contrary to recent findings for some European democracies (Sønderskov \& Dinesen 2016, Seifert 2018), we also find that social trust positively affects political trust. Our results suggest that the positive relationship between both types of trust travels to different political settings, and that there is no minimum threshold required in levels of trust for this relationship to emerge.
\end{abstract}

Keywords Social trust · Political trust $\cdot$ Linear dynamic panel models · Chile

\section{Introduction}

During the last decades, social scientists have accumulated growing evidence showing that social trust and trust in political institutions (political trust hereafter) are substantively important outcomes. Higher social trust has been associated, among other things, with pro-social behaviors (Uslaner, 2000), economic growth (Dincer \& Uslaner, 2010; Whiteley, 2000; Zak \& Knack, 2001), more efficient markets (Fukuyama, 1996), stronger democracies (Newton, 1997; Putnam et al., 1994), and lower crime rates (Uslaner, 2002: ch. 7 and 8). At the individual

Matías Bargsted

mbargsted@uc.cl

1 Instituto de Sociología, Pontificia Universidad Católica de Chile, Vicuña Mackenna 4860,

Macul, 7820436 Santiago, Región Metropolitana, Chile 
level, trustful individuals tend to be happier (Helliwell, Huang \& Wang, 2018), healthier (Kawachi, 2018), more tolerant to social diversity (Uslaner, 2002), and participate more in voluntary associations (Sønderskov, 2011). Political trust, in turn, is indicative of the degree of legitimacy and stability of democratic regimes (Newton \& Norris, 2000; Zmerli, 2014) and encourages solutions to collective problems (Hetherington, 1998), including perhaps two challenges currently threatening humanity - climate change (Fairbrother et al., 2019) and the COVID19 pandemic (Lalot et al., 2020).

A common theme among scholars studying these two types of trust is whether they are causally related to each other. Is social trust a determinant of political trust? Do trustworthy political institutions foster social trust (Rothstein \& Stolle, 2008)? Could both variables influence each other simultaneously? Finding that social and political trust have reciprocal and positive effects, would raise interesting possibilities for designing policies that unleash a virtuous spiral of trust - a spiral badly needed for the economic, environmental, and health challenges facing contemporary societies.

But getting at these kinds of findings is not easy. Trust often appears correlated with multiple other attributes (Nannestad, 2008), and establishing causal links - a challenge for social sciences in general - becomes particularly difficult in this case where concerns about causal simultaneity are salient and plausible. Also, most previous empirical studies use cross-sectional data (Brehm \& Rahn, 1997; Delhey \& Newton, 2005; Dinesen \& Sønderskov, 2015; Kaase, 1999; Mishler \& Rose, 2001; Newton \& Norris, 2000; Newton \& Zmerli, 2011; Zmerli \& Newton, 2008). Thus, they do not provide clear guidelines about how to tackle this issue.

In this paper we ask whether social and political trust affect each other at the individual level using 4-wave panel survey data collected between 2016 and 2019 on a nationally representative sample of 2000 Chilean adults. Our analysis follows the lead of two recent studies that have begun to disentangle the causal relationship between social and political trust using panel data. Sønderskov and Dinesen (2016) revealed that in Denmark trust in state institutions has a positive effect on social trust but not the other way around. Seifert (2018) reached similar conclusions for the Netherlands and Switzerland. While both studies improve on previous research, they are restricted to rich and developed societies with low inequality, generous welfare states, and high trust reservoirs (Delhey \& Newton, 2005).

Here we explore trust in a different, less privileged context, where a virtuous spiral of social and political trust may be more relevant for improving people's wellbeing. Our case study is Chile. As most Latin American countries, Chile has several features that presumably hinder the reproduction of generalized and political trust. It has high income inequality, salient class and ethnic divisions (UNDP, 2017), and targeted social policies that reinforce them. Chileans tend to privilege relations with relatives and friends in detriment of strangers (Valenzuela \& Cousiño, 2000). Not surprisingly, comparative studies found that Chileans exhibit persistent and remarkably low social and political trust (Delhey \& Newton, 2005; Mattes \& Moreno, 2018). Since these features presumably obstruct the vitality of trust, Chile can be seen as an "adjudicative case" (Torche, 2005). If social and political trust affect each 
other in this trust-adverse context, then the mechanisms underlying these relationships might have considerable external validity.

We also extend the statistical modeling framework provided by previous research. We relax some of the strong assumptions commonly conveyed to interpret coefficients as causal parameters by estimating a multiplicity of statistical models with varying specifications and assumptions. These comprise autoregressive models, linear panel models and dynamic linear panel models that include lagged and/or contemporaneous effects. Our empirical results support the institutional view claiming that political trust has a positive effect over social trust. But we also find that, in Chile, social trust affects political trust. The effects of one type of trust over the other are mostly always contemporaneous, and not lagged, and their relative magnitude varies across different assumptions. Under strict exogeneity, the effects of political trust on social trust tend to be larger than the reverse effects. When we relax this assumption to sequential exogeneity, the effects become more symmetric.

We believe our results open new theoretical questions. Here we anticipate two issues which we discuss more thoroughly in the final section. First, the finding that social trust shapes political trusts is noteworthy: it is absent in existing studies using comparable data and methods. Second, by finding reciprocal effects in a very low-trust society like Chile, we suggest that there is no minimum threshold of trust across society for the 'trust synergy' to emerge.

The article is organized as follows. Section 2 describes the theoretical mechanisms underlying the relationship between social and political trust. Section 3 presents the Chilean case and argues for its usefulness for exploring the relationship between trust types. Section 4 presents our statistical framework, and Sect. 5 describes the results. Section 6 summarizes our main findings and discuss their relevance and implications.

\section{Do Social and Political Trust Affect Each Other?}

Social (or generalized) trust refers to the belief that the actions of others will affect positively our own wellbeing, and that others will refrain from selfish, opportunistic, and hostile behavior (Offe, 1999). Political trust, in turn, refers to our positive expectations regarding the behavior of institutions such as the parliament, government, political parties and courts, and of those individuals leading these institutions, which are perceived as competent, credible, and fair (Levi \& Stoker, 2000; Zmerli, 2014). As this definition implies, political trust refers to trust in political institutions, and this is what our measures precisely capture. For the sake of brevity, and following the current scholarly convention (Newton et al., 2018), we refer to "political trust" instead of "institutional trust" or "institutional political trust".

There are at least three views on the causal relations between social and political trust: that they are not related to each other; that political trust influences social trust; and that social trust influences political trust. Next, we review each of them. 


\section{No Causal Relation}

One view is skeptical about reciprocal influences between both types of trust because each would constitute substantially different kinds of phenomena. Some scholars conceive social trust as resulting from genetic features (Mondak et al., 2017) or early socialization stages (Uslaner, 2002). Social trust stabilizes in the early adulthood and remains mostly unaffected by further experiences and information (Abdelzadeh \& Lundberg, 2017). Political trust, in turn, contains an evaluative assessment of political objects based on short-term changes in the performance, credibility, and probity of political actors and institutions. Consequently, political trust could be affected by a myriad of events such as political upheavals, economic crisis, corruption scandals or changes in the ideological profile of governments (Bargsted et al., 2017; Van der Meer \& Hakhverdian, 2017). According to this view, both kinds of trust would have different sources. Thus, we should not expect they affect each other. This implies that the policy measures aimed at shaping them would differ (Badescu \& Uslaner, 2004, p.48).

A similar view expects bivariate correlations based on spuriousness rather than reciprocal influences. Using the World Values Survey, Newton et al. (2018) suggest that social and political trust may be correlated simply because they are determined by a series of individual attributes defining who are the "winners" in a society: those with more wealth, happiness, education, and health show both higher social and political trust. But this does not imply a causal relationship among them.

\section{Political Trust Shapes Social Trust}

The institutional approach suggests that the quality of political institutions, and the kind of policies they promote, can influence mass levels of social trust. Rothstein and Stolle (2008) identify three socio-psychological mechanisms that could account for this pattern: inference, incentives, and consequences. Regarding inference, the authors argue that if citizens believe that public officers - like police officers, bureaucrats, or politicians-behave honestly and impartially, they will infer that the rest would follow the example, making them worthy of trust. Regarding incentives, if institutions are impartial and effective, most people would lack incentives to behave in dishonest ways to obtain benefits. This would make people at large more trustworthy. Regarding consequences, if institutions are fair and effective, behavioral rules will be clear and it will be easier to punish those with opportunistic or selfish behaviors. This would make people more honest and cooperative, prompting higher levels of social trust in general. Additional mechanisms are possible. For instance, Spadaro et al. (2020) claim that trust in state institutions indirectly influence social trust by encouraging feelings of security, which in turn helps people to cope with their own vulnerability and to trust others. 


\section{Social Trust Shapes Political Trust}

Some scholars suggest that social trust affects political trust. One adduced mechanism is projection, whereby the learnings and experiences that individuals cumulate from everyday social interactions serve as a general heuristic that determines their degree of trustworthiness towards public officials (Brehm \& Rahn, 1997; Lipset \& Schneider, 1983; Seifert, 2018). Dellmuth and Tallberg (2020) present a similar mechanism which they term "cooperative expectations": "People who are trusting tend to expect cooperative behavior from others, making them more likely to consider collective political institutions as legitimate" (p.313). They find that social trust is an "antecedent factor" of the legitimacy towards international and domestic political institutions.

A second mechanism refers to institutional performance. Putnam's (1993) classical study of Italy provides a clear illustration. During the twentieth century, Italian regions with historically stronger reservoirs of social capital and generalized trust enjoyed more effective governments, making their citizens to trust highly on their regional political authorities. In a state-level study in the United States, Knack (2002) found that generalized trust increases government performance, which in turn increases political trust. Likewise, Uslaner (2002) argues that higher generalized trust reduces corruption at the national level, and lower corruption is also associated with higher political trust.

In sum, several studies suggest reciprocal influences between social and political trust. Since the mechanisms favoring one causal path are not inconsistent with those favoring the reverse path, both variables might be simultaneously related.

\section{Chile as an Adjudicative Case}

There is wide variation in the levels of social trust across countries. According to the seventh wave of the World Values Survey, the Nordic countries are at the top-on average, about $66 \%$ of their populations trusts others. On the other extreme, Latin America and Sub-Saharan Africa have figures of $14 \%$ and $13 \%$ respectively, representing the most distrusting areas (Mattes \& Moreno, 2018). Chile, with just 13\% of the sample trusting other people, ranks well below many countries, such as Spain (41\%), United States (37\%), South Korea (33\%), France (26\%), Poland (24\%), and Kazakhstan (23\%). A similar pattern can be found for political trust, ranging from $57 \%$ for Asia, 49\% for Nordic countries, and only 29\% for Latin America (Mattes \& Moreno, 2018). During the late 1990s, Chilean society had slightly higher aggregate levels of political trust than the Latin American average, but they began to decline after the mid-2000s and, in recent years, have placed Chile even below the regional average (UNDP, 2020: 55). 
Research focusing on the relation between social and political trust has focused on rich, high-trust societies with relatively low inequality levels, and robust welfare states. Indeed, the best recent evidence about the impact of political trust on social trust comes from panel studies on Denmark (Sønderskov \& Dinesen, 2016), and Netherlands and Switzerland (Seifert, 2018). Do these results travel to low-trust societies?

Chile is an interesting case for answering this question. On the one hand, it is broadly comparable to the abovementioned countries because it has a capitalist economy, a liberal democratic regime, ${ }^{1}$ a Christian cultural heritage, relatively low levels of corruption, ${ }^{2}$ and a mid-high level of human development. ${ }^{3}$ But on the other hand, other features in Chile should inhibit a virtuous, self-reinforcing cycle between social and political trust such as that identified by Rothstein and Uslaner (2005). Chile, as shown above, has low levels of trust, both social (Holmberg \& Rothstein, 2017) and institutional (Segovia, 2008; UNDP, 2020). It has been characterized as a society with a narrow radius of trust - people trust their friends and relatives but are suspicious of those beyond their intimate circles (Valenzuela \& Cousiño, 2000). It has high income inequality - a Gini index of 0.44 in 2017 (World Bank) - which has been politicized during the last decade and a half, resulting in social and political movements resorting to collective protest to change the socioeconomic model (Somma et al., 2021). Its targeted social policies conspire against broad alliances among popular sectors and the upper classes (Korpi \& Palme, 1998).

Given these features, one might expect that in Chile political trust does not affect social trust or the other way around. As noted by Badescu and Uslaner (2004), "Bo Rothstein's Sweden, where the strong underbelly of trust makes for clean government and where honest politicians set a good example for the rest of us, may be too exceptional to serve as an example to countries in transition". However, if social and political trust can influence each other irrespective of how expanded they are in society, or how trustworthy their public servants are, the connection between both types of trust could travel across contexts. This could have interesting policy implications. It would offer an escape from the inequality trap, in which socioeconomic inequality weakens social trust and hinders universalistic welfare policies which require high trust for successful implementation (Rothstein \& Uslaner, 2005).

\section{Statistical Framework}

To uncover the relationship between social and political trust we use panel survey data. We estimate three sets of statistical models that encompass different specifications and varying assumptions, some more restrictive than others. ${ }^{4}$ Our strategy is

\footnotetext{
${ }^{1}$ Categorized as full democracy, according to Democracy Index 2020 (The Economist Intelligence Unit, 2021).

2 Ranked 25th in the world, in the Corruption Perceptions Index 2020 (Transparency International, 2021).

3 Ranked 43rd in the world, in the Human Development Index 2020 (UNDP, 2020).

${ }^{4}$ Panel data can be very helpful to study the causal relationships between variables given the leverage provided by temporal ordering, accounting for unobserved temporally invariant heterogeneity, and by allowing correlation between errors and future observations (sequential exogeneity). However, these causal claims are still sustained by very strong identifying assumptions, which could only be loosened through a randomization-based design.
} 
to identify key patterns that might emerge across varied conditions. This approach also allows us to compare our estimates with results from recent articles that have employed equivalent specifications to those we use here. All the statistical models we estimate can be represented as specific cases of the following unconstrained equations:

$$
\begin{aligned}
& P T_{i t}=\beta_{0}+\rho_{1} P T_{i t-1}+\beta_{1} S T_{i t-1}+\beta_{2} S T_{i t}+x_{i t}^{\prime} \eta_{1}+z_{i}^{\prime} \alpha_{1}+c_{i}+\delta_{1 t}+\mu_{i t} \\
& S T_{i t}=\gamma_{0}+\rho_{2} S T_{i t-1}+\gamma_{1} P T_{i t-1}+\gamma_{2} P T_{i t}+x_{i t}^{\prime} \eta_{2}+z_{i}^{\prime} \alpha_{2}+d_{i}+\delta_{2 t}+\epsilon_{i t}
\end{aligned}
$$

where $P T_{i t}$ and $S T_{i t}$ are the level of political and social trust of individual $i$ in wave $t$, respectively, $\beta_{1}$ and $\gamma_{1}$ are the cross-lagged coefficients, $\beta_{2}$ and $\gamma_{2}$ are the crosscontemporaneous coefficients, and $\rho_{1}$ and $\rho_{2}$ are the autoregressive coefficients. Both models include a vector of control variables that vary across time $\left(x_{i t}^{\prime}\right)$ and that are temporally invariant $\left(z_{i}^{\prime}\right)$. The terms $c_{i}$ and $d_{i}$ are individual specific effects that capture unobserved and temporally invariant characteristics associated to respondent $i$. Both terms freely correlate with all covariates included in each equation and are not subject to any parametric assumptions. Lastly, $\delta_{1 t}$ and $\delta_{2 t}$ capture temporal variations associated to the wave $t$ of all survey respondents. The residuals terms $\mu_{i t}$ and $\epsilon_{i t}$ are assumed independent and identically distributed.

Following Sønderskov and Dinesen (2016), our first set of models are crosslagged panel equations, which are obtained by imposing the constrains $\beta_{2}=0, c_{i}=$ 0 and $\gamma_{2}=0, d_{i}=0$ in Eq. (1) and (2), respectively. ${ }^{5}$ The model assumes that the effect of social (political) trust over political (social) trust is completely lagged, and that no contemporaneous effect exists. An important strength of this model is that, by including an autoregressive coefficient, it allows for dynamics in the underlying process which may prove crucial for recovering consistent estimates of other parameters, even if they are not of substantive interest (Bond, 2002). We also consider variations of the cross-lagged panel model, by estimating models that release $\beta_{2}$ and $\gamma_{2}$, but constrain the lagged effects $\left(\beta_{1}=0, \gamma_{1}=0\right)$, which corresponds to a simple autoregressive model, and lastly, a model where both contemporaneous and lagged crossed variables are freely estimated, but still with the important restriction of $c_{i}=$ 0 and $d_{i}=0$. All these models are estimated through pooled OLS under the assumption of strict exogeneity of the covariates.

Our second set of models, following both Sønderskov and Dinesen (2016) and Seifert (2018), correspond to linear panel models. These entail constraining the autoregressive coefficient in Eq. (1) and (2) to zero: $\rho_{1,2}=0$. The vector of parameters $\boldsymbol{\alpha}_{1}$ and $\boldsymbol{\alpha}_{2}$ are not identified either since all cross-sectional variation is absorbed by the terms the $c_{i}$ and $d_{i}$. By including these terms, this model relaxes the exogeneity assumption from strict exogeneity to strict exogeneity conditional on unobserved effects (Wooldridge, 2010, pp. 287-289). While these models omit any possible autoregressive dynamic in the evolution of social and political trust, we can explore

\footnotetext{
5 The constrains $c_{i}=0$ and $d_{i}=0$ imply delegating all between-subject unobserved heterogeneity to the error terms $\mu_{i t}$ and $\epsilon_{i t}$, which of course, makes the assumptions of no correlation between theses errors and the covariates in the model increasingly implausible.
} 
whether the effects of either of the trust variables over the other is contemporaneous only $\left(\beta_{2}=0, \gamma_{2}=0\right)$, lagged only $\left(\beta_{1}=0, \gamma_{1}=0\right)$, or a combination of both (no restrictions save $\left.\rho_{1,2}=0\right)$. We estimate these models by using the first differences between wave $t$ and $t-1$ of the dependent and independent variables, and then applying OLS.

The third set of models we consider, not considered by previous research, are dynamic linear panel models (Wawro, 2002). They are obtained by constraining the vectors $\boldsymbol{\alpha}_{1}$ and $\boldsymbol{\alpha}_{2}$ to zero, though they include individual fixed effects $\left(c_{i}\right.$ and $\left.d_{i}\right)$. By incorporating both an autoregressive term and an individual level fixed effect, the model can account simultaneously for state dependence and unobserved temporally invariant heterogeneity (Hyslop, 1999). We estimate these models through Difference Generalized Method of Moments proposed by Arellano and Bond (1991) - also commonly known as the Arellano-Bond estimator. This entails taking the first differences of each component of the model, which cancels out the individual level fixed effect:

$$
\begin{aligned}
& \Delta P T_{i t}=\rho_{1} \Delta P T_{i t-1}+\beta_{1} \Delta S T_{i t-1}+\beta_{2} \Delta S T_{i t}+\Delta x_{i t}^{\prime} \alpha_{1}+\delta_{t 1}+\Delta \mu_{i t} \\
& \Delta S T_{i t}=\rho_{2} \Delta S T_{i t-1}+\gamma_{1} \Delta P T_{i t-1}+\gamma_{2} \Delta P T_{i t}+\Delta x_{i t}^{\prime} \alpha_{2}+\delta_{t 2}+\Delta \epsilon_{i t}
\end{aligned}
$$

where $\Delta$ is the difference operator, such that: $\Delta P T_{i t}=P T_{i t}-P T_{i t-1}$. In Eqs. 3 and 4 the differenced lagged dependent variable is correlated with the errors through $P T_{i t-1}$ and $\mu_{i t-1}$ in Eq. 3 and $S T_{i t-1}$ and $\epsilon_{i t-1}$ in Eq. 4. Anderson and Hsiao (1982) showed that $P T_{i t-2}$ can be used as an instrument for $\Delta P T_{i t-1}$, and $S T_{i t-2}$ as an instrument for $\Delta S T_{i t-1}$, which, under the assumption of no serial correlation of the errors, are uncorrelated with $\Delta \mu_{i t}$ and $\Delta \epsilon_{i t}$, respectively. Arellano and Bond (1991) extended this logic and suggested using all available lags as instruments.

The dynamic linear panel model has one additional property that we exploit in our analysis. The effects of $S T_{i t}$ and $P T_{i t}$ in Eqs. 3 and 4 can be estimated under the milder assumption of sequential exogeneity instead of strict exogeneity; this implies that $P T_{i t}$ and $S T_{i t}$ are independent of the contemporaneous and future residual errors but can be correlated with past values, which allows for feedback effects between $P T_{i t}$ and $S T_{i t+1}$ in Eq. (1), and $S T_{i t}$ and $P T_{i t+1}$ in Eq. (2) (Bond, 2002; Wooldridge, 2010 , pp. 368-374). To attain this, we employ $S T_{i t-1}$ and further lags as instruments of $\Delta S T_{i t}$ in Eq. 3, and $P T_{i t-1}$ and further lags as instruments of $\Delta P T_{i t}$ in Eq. 4. According to Reed (2015) using lagged values of the endogenous explanatory variable as instruments is a reliable estimation strategy if two conditions hold: (a) the lagged values do not themselves belong in the respective estimating equation, that is, there is no true lagged effect; and (b) the endogenous covariate is sufficiently auto-correlated such that the weak instrument problem does not apply. Following Leszczensky and Wolbring (2019), the first assumption could be relaxed if the panel has more than three waves by including both a lagged and contemporaneous covariate each instrumented with available previous values. 
We estimate and contrast models that include lagged and contemporaneous independent variables for two reasons. First, we have no theoretical guidance regarding the timing of the effects of one type of trust over the other, and therefore it seems unwise to consider ex ante only one type of effect. Second, models that only include a lagged effect, such as the cross-lagged panel model, have the potential advantage of circumventing endogeneity biases related to simultaneous causation, but this comes at the expense of strong and unrealistic assumptions (Bellemare et al., 2017). One of them is that the true causal lag between covariates and the dependent variable corresponds to the actual time elapsed between panel waves (Finkl 1995). ${ }^{6}$ Methodological studies confirm this point by showing that unbiased estimation of causal effects with panel data hinges critically on the correct specification of the temporal lags (Leszczensky \& Wolbring, 2019; Reed, 2015; Vaisey \& Miles, 2017). Reed (2015) and Vaisey and Miles (2017) show that when a lagged predictor is used to capture a true contemporaneous effect, the recovered coefficients can have the opposite sign of the true effect, even when accounting for unobserved heterogeneity. The extensive Monte Carlo analysis of Leszczensky and Wolbring (2019) suggest that dynamic linear panel models that include both lagged and contemporaneous predetermined regressors represent an effective strategy to account simultaneously for unknown temporal dependence and reciprocal influences among covariates. ${ }^{7} \mathrm{We}$ include this precise specification among the wide set of statistical models that we consider in the next section.

\section{Data and Measurement}

We use the Chilean Longitudinal Social Survey (ELSOC), a unique panel survey that has annually interviewed a representative probability-based sample of Chilean adults (18 or older) located in urban areas (cities of more than 10,000 inhabitants) since $2016 .{ }^{8}$ We include all available years in our analysis, which amounts to four waves between 2016 and 2019. The last wave was applied before the Coronavirus worldwide pandemic, and right after major street protests initiated in Chile since mid-October 2019 (Somma et al., 2021).

To measure social trust we created a composite index based on three survey items employed in many social surveys: "Generally speaking, would you say that most

\footnotetext{
6 This assumption seems very stringent even in cases of annual panels and becomes even more so as the extension of the lag between panel wave increases.

7 Leszczensky \& Wolbring (2019) favor using a cross-lagged panel model with fixed effects proposed by Moral-Benito et al. (2019), instead of the well-known Arellano-Bond estimator. We opt in favor of the later given that their simulations show that both perform remarkably well in the presence of unobserved heterogeneity and reverse causality.

8 This survey includes two samples: an original sample that has been interviewed annually since 2016, and a second refreshment sample initiated in 2018. The sample size of the first wave was 2927 cases, of which 1913 were still participating in 2019, entailing an overall attrition rate of $35 \%$ after 4 waves of data collection. Further methodological details about the survey, as well as datasets, can be downloaded at the Data Repository of the Centre for Social Conflict and Cohesion Studies (COES) located in the Harvard Dataverse: https://dataverse.harvard.edu/dataverse/coes_data_repository.
} 
people can be trusted, or that you have to be careful when dealing with them?", "Would you say that people, most of the time, try to help others, or do they care mostly only about themselves?", and "Do you think most people would try to take advantage of you if they had the chance, or do you think they would try to be fair?". In addition to the response alternatives contained in the survey question, respondents could opt for a third unread alternative, "It depends". Each item was coded with values from 1 to 3, assigning higher scores to response categories that indicate greater social trust. We built a simple index by computing the arithmetic mean of the three items for each wave of the survey. We analyzed each scale with the ordinal alpha consistency indicator, suitable for ordinal items (Gadermann et al., 2012), which shows reasonable (though a bit low) and stable values across waves ( $\alpha_{t=1}=0.66$, $\alpha_{t=2}=0.68, \alpha_{t=3}=0.65$, and $\alpha_{t=4}=0.69$ ).

Political trust is also measured as a composite index based on four survey items that ask survey respondents how much they trust four political institutions. The wording is: "Could you tell me how much you trust each of the following institutions?": "The government", "Political parties", "Congress", and "The Judiciary System". Answers range from 1 ("Nothing") to 5 ("A lot"). The index was also constructed as the average value of the four items for each wave. It shows a stable and relatively high degree of internal consistency, according to the ordinal alpha statistic $\left(\alpha_{t=1}=0.84, \alpha_{t=2}=0.86, \alpha_{t=3}=0.83\right.$, and $\left.\alpha_{t=4}=0.86\right)$. To facilitate the comparison of the regression coefficients, both trust indexes were rescaled to vary from zero to one in each wave. ${ }^{9}$

Control variables. Many studies have shown that social and political trust vary significantly along many individual characteristics and circumstances. The linear and linear dynamic panel models we employ account for all observed or unobserved traits that do not vary in time, such as genetic predispositions, personality traits, and pre-adult socialization processes, among others. The cross-lagged panel model instead can only control for observable temporally invariant variables. Among possible candidates we include sex, educational degree, and age at their value at wave 1 of the study. All three sets of models also include variables that vary in time and that have been shown to be relevant by previous research, namely employment status, life satisfaction, frequency of church attendance, and left-right orientation (Brehm \& Rahn, 1997; Glanville \& Paxton, 2007; Lindstrom \& Mohseni, 2009; Newton et al., 2018). In the online supplement we provide the details about survey wording and coding of all the variables included in the study (section B), as well as their summary statistics (section C).

\footnotetext{
${ }^{9}$ Contrary to Sønderskov \& Dinesen (2017) and Seifert (2018) we excluded the Police from the political trust index because this institution did not load well on a single factor in a confirmatory factor analysis that included all five public institutions. Police factor loadings were substantively lower in all waves (averaging 0.56 unlike the rest of the items whose factor loadings were always above to 0.73). Additionally, when adding the Police item to the model the fit indices deteriorate, RMSEA increases from 0.029 to $0.050, \mathrm{Chi}^{2} / \mathrm{gl}$ grows from 2.5 to 5.4 and CFI/TLI decreases from $0.997 / 0.995$ to $0.987 / 0.982$.
} 

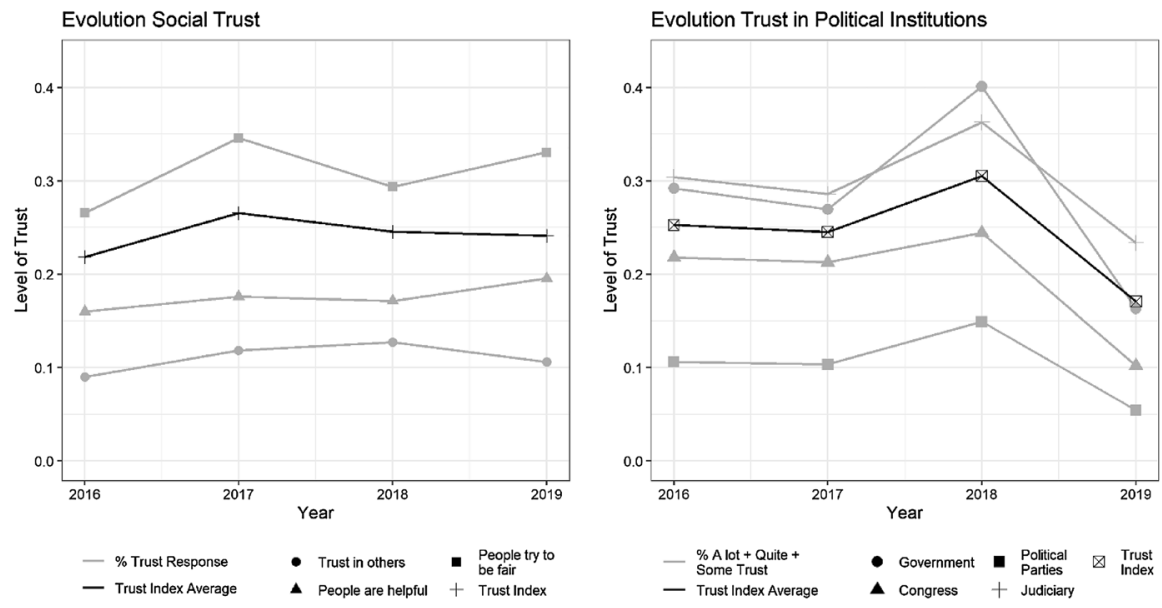

Fig. 1 Evolution of social and political trust indexes and items across four waves of the ELSOC survey panel (weighted estimates)

\section{Results}

Before turning to the regression models, we briefly consider some interesting descriptive trends contained in Fig. $1 .{ }^{10}$ The grey lines of both plots show the evolution of the proportion of favorable responses to each social trust item, and the proportion of the sum of responses 'A lot', 'Quite' and 'Some' trust for each political institution we consider, respectively. The black lines show the average score of each composite index. As can be seen, social and political trust indicators in Chile are consistently low across time. While the perception of 'people try to be fair' ranks higher, reaching over 30\% in 2017 and 2019, the proportion of trustful responses of the other two items consistently locate below $20 \%$ during all years. Similarly, trust in government and the judiciary rose in 2018, but during the years before and especially after, they decline dramatically. This reflects, presumably, changes in citizens' evaluations due to the social outbreak of late 2019 (Somma et al., 2021). Congress and political parties show dramatically low support; trust in political parties reaches single-digit figures during our observed period.

Table 1 shows the estimates obtained from the cross-lagged and cross-contemporaneous panel models. Controlling for a relevant number of covariates, models 1 and 2 indicate that both lagged and contemporaneous political trust positively and significantly $(p<0.01)$ predict levels of social trust. ${ }^{11}$ The contemporaneous coefficient $\left(\widehat{\gamma_{2}}=0.16\right)$ is larger than the lagged coefficient $\left(\hat{\gamma_{1}}=0.11\right)$ when estimated separately. When both predictors are included in a single model both remain significant

\footnotetext{
10 The data and code necessary to replicate all results detailed in the article and Online Supplement are available at: https://doi.org/10.7910/DVN/QWYXTK.

11 The tables in the article only show the estimated parameters of the key predictors. Full results, including coefficients from the control variables, are available in the Online Supplement (section D).
} 
Table 1 Cross-lagged and cross-contemporaneous panel models for social and political trust

\begin{tabular}{|c|c|c|c|c|c|c|}
\hline & \multicolumn{3}{|c|}{ DV: Social Trust ${ }_{t}$} & \multicolumn{3}{|c|}{ DV: Political Trust ${ }_{t}$} \\
\hline & Model 1 & Model 2 & Model 3 & Model 4 & Model 5 & Model 6 \\
\hline Intercept & $\begin{array}{l}0.092^{* * *} \\
(0.024)\end{array}$ & $\begin{array}{l}0.092^{* * *} \\
(0.024)\end{array}$ & $\begin{array}{l}0.090^{\text {**** }} \\
(0.024)\end{array}$ & $\begin{array}{l}0.031 \\
(0.018)\end{array}$ & $\begin{array}{l}0.028 \\
(0.018)\end{array}$ & $\begin{array}{l}0.026 \\
(0.018)\end{array}$ \\
\hline Political Trust $_{\mathrm{t}-1}$ & $\begin{array}{l}0.112^{* * *} \\
(0.017)\end{array}$ & & $\begin{array}{l}0.057^{* *} \\
(0.018)\end{array}$ & $\begin{array}{l}0.395^{* * *} \\
(0.014)\end{array}$ & $\begin{array}{l}0.387^{* * *} \\
(0.014)\end{array}$ & $\begin{array}{l}0.388^{\text {**** }} \\
(0.014)\end{array}$ \\
\hline Political Trust ${ }_{t}$ & & $\begin{array}{l}0.161^{\text {**** }} \\
(0.018)\end{array}$ & $\begin{array}{l}0.136^{* * *} \\
(0.020)\end{array}$ & & & \\
\hline Social Trust $_{\mathrm{t}-1}$ & $\begin{array}{l}0.239^{* * *} \\
(0.017)\end{array}$ & $\begin{array}{l}0.242^{\text {*** }} \\
(0.017)\end{array}$ & $\begin{array}{l}0.236^{* * *} \\
(0.017)\end{array}$ & $\begin{array}{l}0.017 \\
(0.010)\end{array}$ & & $\begin{array}{l}0.001 \\
(0.011)\end{array}$ \\
\hline Social Trust $_{\mathrm{t}}$ & & & & & $\begin{array}{l}0.075^{\text {*** }} \\
(0.010)\end{array}$ & $\begin{array}{l}0.075^{\text {*** }} \\
(0.011)\end{array}$ \\
\hline Wave 2018 & $\begin{array}{l}-0.036^{* * *} \\
(0.009)\end{array}$ & $\begin{array}{l}-0.041^{* * *} \\
(0.009)\end{array}$ & $\begin{array}{l}-0.041^{* * *} \\
(0.009)\end{array}$ & $\begin{array}{l}0.032^{* * *} \\
(0.007)\end{array}$ & $\begin{array}{l}0.034^{\text {**** }} \\
(0.007)\end{array}$ & $\begin{array}{l}0.033^{\text {*** }} \\
(0.007)\end{array}$ \\
\hline Wave 2019 & $\begin{array}{l}-0.042^{* * * *} \\
(0.008)\end{array}$ & $\begin{array}{l}-0.022^{* *} \\
(0.008)\end{array}$ & $\begin{array}{l}-0.027^{* * * *} \\
(0.008)\end{array}$ & $\begin{array}{l}-0.105^{\text {*** }} \\
(0.006)\end{array}$ & $\begin{array}{l}-0.104^{* * *} \\
(0.006)\end{array}$ & $\begin{array}{l}-0.104^{\text {*** }} \\
(0.006)\end{array}$ \\
\hline $\mathrm{R}^{2}$ & 0.102 & 0.109 & 0.111 & 0.275 & 0.282 & 0.284 \\
\hline Adj. $\mathrm{R}^{2}$ & 0.099 & 0.107 & 0.106 & 0.273 & 0.280 & 0.281 \\
\hline Num. obs & 5606 & 5605 & 5595 & 5613 & 5629 & 5595 \\
\hline
\end{tabular}

(1) Robust standard error in parentheses clustered at the level of respondents. (2) Complete results are available in the Online Supplement

$* * * p<0.001$

$* * p<0.01$

$* p<0.05$

$(p<0.01)$, but decrease in size, particularly the lagged effects which is reduced in $50 \%$. Based on the estimates from model 3, a variation from minimum to maximum of contemporaneous political trust amounts to $51 \%$ of a standard deviation of social trust, whereas an equal variation in lagged political trust amounts to $21 \%$.

When we consider the effects of social trust over political trust, we find a statistically negligible lagged effect, either when current social trust is omitted or included in the equation (models 4 and 6 , respectively). In contrast, the contemporaneous effect is positive and statistically significant $(p<0.01)$ and has the same size whether estimated with or without lagged social trust $\left(\hat{\beta}_{2}=0.075\right)$. A variation from minimum to maximum of contemporaneous social trust entails $33 \%$ of a standard deviation of political trust, which certainly is far from negligible. This finding contrasts with those reported by Seifert (2018) and Sønderskov and Dinesen (2016) for Denmark, Netherlands and Switzerland, where social trust does not influence political trust. $^{12}$

\footnotetext{
12 Section E of the Online Supplement includes a batch of models that employ a slightly modified version of the political trust composite index that makes it more similar to the measure employed by Sønderslev and Dinesen (2016) in their analysis with the Danish Social and Political Attitudes Survey.
} 
Table 2 Linear panel models for social and political trust

\begin{tabular}{|c|c|c|c|c|c|c|}
\hline & \multicolumn{3}{|c|}{ DV: Social trust $t_{t}$} & \multicolumn{3}{|c|}{ DV: Political trust $t_{t}$} \\
\hline & Model 7 & Model 8 & Model 9 & Model 10 & Model 11 & Model 12 \\
\hline Political Trust ${ }_{\mathrm{t}-1}$ & $\begin{array}{l}0.001 \\
(0.025)\end{array}$ & & $\begin{array}{l}0.055^{*} \\
(0.026)\end{array}$ & & & \\
\hline Political Trust $_{\mathrm{t}}$ & & $\begin{array}{l}0.109^{* * *} \\
(0.027)\end{array}$ & $\begin{array}{l}0.134^{* * *} \\
(0.028)\end{array}$ & & & \\
\hline Social Trust ${ }_{\mathrm{t}-1}$ & & & & $\begin{array}{l}-0.035^{* *} \\
(0.013)\end{array}$ & & $\begin{array}{l}-0.010 \\
(0.014)\end{array}$ \\
\hline Social Trust ${ }_{t}$ & & & & & $\begin{array}{l}0.056^{* * *} \\
(0.014)\end{array}$ & $\begin{array}{l}0.053^{* * *} \\
(0.015)\end{array}$ \\
\hline Wave 2018 & $\begin{array}{l}-0.022^{* *} \\
(0.008)\end{array}$ & $\begin{array}{l}-0.027^{\text {**** }} \\
(0.008)\end{array}$ & $\begin{array}{l}-0.029^{* * *} \\
(0.008)\end{array}$ & $\begin{array}{l}0.044^{* * *} \\
(0.006)\end{array}$ & $\begin{array}{l}0.044^{* * *} \\
(0.006)\end{array}$ & $\begin{array}{l}0.044^{* * *} \\
(0.006)\end{array}$ \\
\hline Wave 2019 & $\begin{array}{l}0.014 \\
(0.013)\end{array}$ & $\begin{array}{l}0.032^{*} \\
(0.014)\end{array}$ & $\begin{array}{l}0.035^{*} \\
(0.014)\end{array}$ & $\begin{array}{l}-0.164^{* * *} \\
(0.009)\end{array}$ & $\begin{array}{l}-0.164^{* * *} \\
(0.009)\end{array}$ & $\begin{array}{l}-0.163^{\text {*** }} \\
(0.009)\end{array}$ \\
\hline $\mathrm{R}^{2}$ & 0.003 & 0.009 & 0.011 & 0.132 & 0.137 & 0.137 \\
\hline Adj. $\mathrm{R}^{2}$ & 0.001 & 0.007 & 0.008 & 0.130 & 0.135 & 0.134 \\
\hline Num. obs & 3711 & 3709 & 3703 & 3682 & 3709 & 3679 \\
\hline
\end{tabular}

(1) Robust standard error in parentheses clustered at the level of respondents. (2) Complete results are available in the Online Supplement

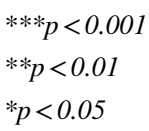

One last important result contained in Table 1 refers to the levels of stability of the dependent variables. The autoregressive coefficients of political trust $\left(\hat{\rho}_{1}=0.39\right)$ are considerably larger than those of social trust $\left(\hat{\rho}_{2}=0.24\right)$. While the former amounts to more than one standard and a half of political trust, the later equals $89 \%$ of a standard deviation of social trust. This result seems at odds with the literature that describes social trust as a stable attitude, supposedly linked to early socialization processes. We will return to this issue when we revise the results from the $A B$ models.

Footnote 12 (continued)

Whereas they measure institutional trust including trust in Parliament, Judiciary, the Police and in Politicians, the estimates of section E include Congress, Judiciary, Police and Political parties. These estimates are virtually identical to the ones reported in the article, and consequently suggest that differences in obtained patterns between Chile and Scandinavian countries might be less likely to be measurement differences than to different statistical specifications or opinion formation processes taking place between countries. 
We now move to the linear panel models in Table 2. In model 7 the coefficient of lagged political trust predicting social trust is very small and non-significant $\left(\widehat{\gamma_{1}}=0.001\right)$, whereas it increases in size and significance $\left(\widehat{\gamma_{1}}=0.06 ; p<0.05\right)$ when estimated in companion of current political trust. The effect of this last variable is considerably larger $\left(\hat{\gamma_{2}}=0.11\right.$ in model $8 ; \widehat{\gamma_{2}}=0.13$ in model 9$)$, and highly significant $(p<0.001)$. Interestingly, the point estimates from the linear panel model with both current and lagged political trust (model 9) are almost identical to those of the equivalent cross-lagged panel model (model 3). Therefore, we observe in Chilean society an equivalent pattern than that uncovered by Seifert (2018) and Sønderskov and Dinesen (2016) for some European democracies, where positive changes in trust in political institutions partially translate into rising social trust.

The effects of social trust over political trust are contained models 10 through 12. The lagged coefficient of social trust is, somewhat unexpectedly, negative $\left(\widehat{\beta}_{2}=-0.04\right)$ and significant at a $99 \%$ level of confidence when estimated alone in model 10 . However, it strongly decreases in magnitude $\left(\hat{\beta}_{2}=-0.01\right)$ and becomes non-significant when contemporaneous social trust is added to the model. The negative effect of lagged social trust is consistent with Reed's (2015) and Vaisey and Miles's (2017) finding that the coefficient of a lagged independent variable can become badly biased when the true effect is contemporaneous. In models 11 and 12 the coefficient of current social trust is positive, highly significant $(p<0.001)$ and of similar magnitude across both specifications. The estimates from model 12 are also similar to those of the equivalent pooled OLS model from Table 1 (model 6), though the contemporaneous effect is slightly smaller, 0.053 versus 0.075 .

Lastly, we consider the results from the Arellano-Bond estimator (AB). The AB estimates of Eqs. 1 and 2 under strict exogeneity are very similar to those of the linear panel models. ${ }^{13}$ The contemporaneous effect of political trust over social trust (models 13 through 15 in Table 3 ) are positive, relatively sizable, and highly significant $(p<0.001)$, while the lagged effect is $60 \%$ smaller and marginally significant in the model that includes both lagged and contemporaneous predictors (otherwise is undistinguishable from zero, just as in the linear panel models).

The AB estimates of the effect of social trust over political trust under strict exogeneity share the same patterns observed in the linear panel models (models 19 through 21 in Table 4). The contemporaneous effect of social trust is positive, significant $(p<0.01)$ and of similar size when estimated alone $\left(\hat{\beta}_{2}=0.056\right)$ or in conjunction with the lagged predictor $\left(\hat{\beta}_{2}=0.048\right)$. The effect of this last variable, just as in the linear panel models, is negative and significant when estimated alone $\left(\widehat{\beta_{2}}=-0.044, p<0.01\right)$, but becomes smaller and non-significant when estimated with the contemporaneous predictor $\left(\widehat{\beta}_{2}=-0.021\right)$.

\footnotetext{
13 All AB models were estimated using the two-step covariance matrix, which yields more efficient estimates in case of heteroscedasticity (Wawro, 2002). In general, we employed as instruments two lags behind for each predetermined regressor, whether the lagged dependent variable, or the contemporaneous trust or lagged trust covariate. We only reduced to one lag in the case of the lagged dependent variable of models predicting political trust given that they performed better in the Sargan specification tests.
} 
Table 3 Dynamic linear panel models for social trust

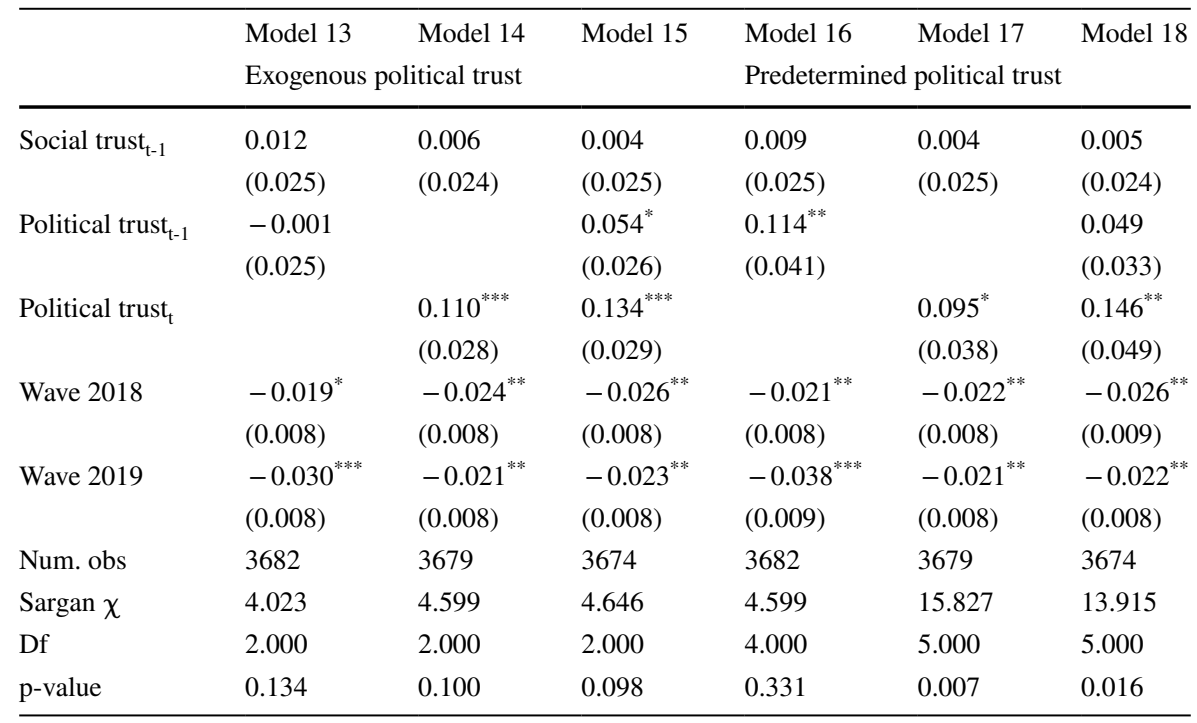

(1) Robust standard error in parentheses clustered the level of respondents. (2) Complete results are available in the Online Supplement

$* * * p<0.001$

$* * p<0.01$

${ }^{*} p<0.05$

Another interesting result, which resembles the findings in Table 1, is the larger autoregressive component of political trust compared to social trust. The autoregressive effect of social trust is nearly equal to zero in all models, adding little, if any, explanatory power after accounting for unobserved heterogeneity. All the autocorrelation in social trust visible in models 1 through 3 in Table 1 was due to unobserved temporally invariant heterogeneity, and consequently an individual's level of social trust drifts around their own fixed intercept; citizens who are above or below their expected level of social trust at one wave are expected to quickly return to their long-term equilibrium. Instead, political trust has more memory. Perturbations in the levels of political trust in one wave, perhaps due to a corruption scandal or a successful political episode, endures over time before they eventually regress to their long-term equilibrium.

What happens when the trust covariates are considered predetermined (or sequentially exogenous)? Overall, the results obtained under strict exogeneity tend to be confirmed, though some discrepancies emerge. We start considering the effect of political trust over social trust contained in models 16 through 18 in Table 3. Caution is required given that model 17 and 18 (which include contemporaneous effects) do not pass the Sargan overidentifying restriction test. ${ }^{14}$ Nonetheless, models 17 through 18

14 These two models show significant first order serial correlations of the differenced residuals $(p<2.2 e$ 16) proposed by Arellano \& Bond (1991), which suggests independence of the residuals of Eqs. 1 and 2. 
Table 4 Dynamic linear panel models for political trust

\begin{tabular}{|c|c|c|c|c|c|c|}
\hline & Model 19 & Model 20 & Model 21 & Model 22 & Model 23 & Model 24 \\
\hline & Exogenous & cial trust & & Predetermi & d social trust & \\
\hline Political Trust $_{\mathrm{t}-1}$ & $0.196^{* * *}$ & $0.188^{* * *}$ & $0.193^{* * *}$ & $0.195^{* * *}$ & $0.178^{* * *}$ & $0.178^{* * *}$ \\
\hline & $(0.033)$ & $(0.033)$ & $(0.033)$ & $(0.034)$ & $(0.033)$ & $(0.033)$ \\
\hline Social Trust $_{\mathrm{t}-1}$ & $-0.044^{* *}$ & & -0.021 & 0.028 & & 0.014 \\
\hline & $(0.015)$ & & $(0.016)$ & $(0.018)$ & & $(0.018)$ \\
\hline Social Trust $_{t}$ & & $0.057^{* * *}$ & $0.049^{* *}$ & & $0.111^{* * *}$ & $0.120^{* * * *}$ \\
\hline & & $(0.016)$ & $(0.017)$ & & $(0.020)$ & $(0.026)$ \\
\hline Wave 2018 & $0.040^{* * *}$ & $0.040^{* * *}$ & $0.040^{* * *}$ & $0.036^{* * *}$ & $0.041^{* * *}$ & $0.039^{* * *}$ \\
\hline & $(0.006)$ & $(0.006)$ & $(0.006)$ & $(0.006)$ & $(0.006)$ & $(0.006)$ \\
\hline Wave 2019 & $-0.089^{* * *}$ & $-0.089^{* * *}$ & $-0.088^{* * *}$ & $-0.091^{* * *}$ & $-0.086^{* * *}$ & $-0.086^{* * *}$ \\
\hline & $(0.006)$ & $(0.006)$ & $(0.006)$ & $(0.007)$ & $(0.006)$ & $(0.006)$ \\
\hline Num. obs & 3677 & 3703 & 3674 & 3677 & 3703 & 3674 \\
\hline $\operatorname{Sargan} \chi$ & 0.134 & 0.102 & 0.167 & 3.274 & 7.636 & 10.943 \\
\hline Df & 1 & 1 & 1 & 3 & 4 & 4 \\
\hline p-value & 0.714 & 0.750 & 0.683 & 0.351 & 0.106 & 0.027 \\
\hline
\end{tabular}

(1) Robust standard error in parentheses clustered the level of respondents. (2) Complete results are available in the Online Supplement

$* * * p<0.001$

$* * p<0.01$

$* p<0.05$

show that the coefficients of contemporaneous political trust are very similar in size than those obtained under strict exogeneity, though their standard errors become larger and the significant lagged effect in model $15(p<0.05)$ is no longer so in model 18 .

The influence of social trust over political trust under sequential exogeneity (models 22 through 24) also corroborate the results under strict exogeneity (models 19 through 21) but with a twist. The estimates continue to indicate a positive and significant effect of contemporaneous social trust and a null effect of lagged social trust, but now the effect of the former doubles in size, from $\widehat{\beta}_{2}=0.049$ in model 21 to $\hat{\beta}_{2}=0.12$ in model 24 . Whereas a variation from minimum to maximum of contemporaneous social trust under strict exogeneity entails $21 \%$ of a standard deviation of political trust, under sequential exogeneity this effect increases up to $52 \%$. Caution is also required because the Sargan test is rejected at a $95 \%$ level of confidence in model 24. But this seems less problematic given that, when estimated alone in model 23, the results are very similar, and in this case the Sargan test can be rejected with the same or higher level of confidence. Therefore, the dynamic linear panel models, under varying assumptions, provide further support to the notion that political trust influences social trust, while the later also affects the former, a pattern not found neither by Sønderskov and Dinesen (2016) nor Seifert (2018) in their study

Footnote 14 (continued)

Therefore the rejection of the Sargan test must be due to some other specification problem, possibly an eventual correlation between the instruments and the errors. 
of European democracies. This leads to somewhat an ironic contrast. Social trust appears to influence political trust in a society where it is chronically low, whereas it does not in societies where social trust is much more abundant.

\section{Conclusions}

We obtain four major findings from the diverse set of statistical models. First, there is clear evidence of a reciprocal, but not necessarily symmetrical, casual relationship between social and political trust in contemporary Chile. While the causal arrow from political to social trust has been found in several European countries (Seifert, 2018; Sønderskov \& Dinesen, 2016; Spadaro et al., 2020), we also found that social trust also impacts political trust positively. The relative size of each effect depends on the assumptions we impose on the data. Under strict exogeneity the effect of political trust is relatively large and doubles the effect of social trust. When estimated under sequential exogeneity, obtained exclusively through the $\mathrm{AB}$ estimator, they become much more similar, and relatively large in both cases.

However, many models allowing predetermined regressors experience some misspecification issues, so conclusions must be taken with caution. Likewise, one of our key variables, social trust, is measured with a relatively low level of reliability, which could imply the contamination of our estimates with measurement error in unknown directions. This is a relevant limitation since measurement error is generally expected to be more consequential in panel data than in cross-section data (Meijer et al., 2014). Despite these limitations, it is not clear whether the absence of social trust effects in previous studies could emerge under more flexible statistical specifications, as the ones employed in this article. Or perhaps, there is something specific about Chilean (or Latin American) society, or low trust societies in general, that explains the effect of social trust. This is an interesting puzzle that future research should address.

Second, in Chile the influence of one type of trust over the other is mostly contemporaneous, and not lagged. Once the contemporaneous predictor is included in the models, the lagged coefficients are either null or much smaller in magnitude. This result, we believe, calls for more theoretical consideration on the timing with which individuals update their levels of trust in particular-and political opinions in general. It could be very useful to systematically explore how variations in timing between measurement occasions might lead to a more accurate empirical depiction of the determinants of opinion formation and change. Likewise, the prevalence of contemporaneous effects in our research also suggest that care should be taken when researchers using panel data simply lag a covariate of interest to exogenize it. More methodological investigation regarding under what conditions can lagged variables serve as effective instruments, and consequently how can the strict exogeneity assumption be somewhat relaxed, could be extremely useful.

Third, our results show that in Chile, after accounting for unobserved temporally invariant heterogeneity, political trust has a much larger autoregressive effect than social trust, something at odds with the common view of social trust as a culturally ingrained trait. Our results speak in favor of a view of social trust as a malleable attribute, whose variation between waves has short temporal endurance. An interesting puzzle emerges 
from this pattern: Why is aggregate social trust so stable across time, but so temporally variable within individuals? The null autoregressive coefficient of social trust in the AB models provides a possible hint. Indeed, if perturbations occurring a given year quicky dilute and individuals rapidly return to their long-term equilibrium (captured by the individual-level fixed effect), then the aggregate level of social trust would also tend to return, after past perturbations, to its previous values. This alternative requires further analysis to be validated, but it constitutes an interesting possibility.

Lastly, our case study shows that the positive causal nexus between social and political trust can emerge even in societies with chronically low trust levels. Interestingly, this "trusts synergy" does not require high o medium trust levels across society. There is no minimum threshold of trust in institutions for influencing trust in the other people, or vice versa. This is good news: it suggests that Rothenstien and Uslaner's (2005) inequality trap could be avoided.

Acknowledgements We thank Luis Maldonado, our anonymous reviewers and the editors of Political Behavior for their valuable comments. We also thank the support of Chile's National Agency for Research and Development (ANID) through a FONDECYT Regular grant (\#1200534) and the Centre for Social Conflict and Cohesion Studies (COES) (ANID/FONDAP/15130009).

Data Availability Data and code to reproduce the results in the article are available at https://doi.org/10. 7910/DVN/QWYXTK.

\section{References}

Abdelzadeh, A., \& Lundberg, E. (2017). Solid or flexible? Social trust from early adolescence to young adulthood. Scandinavian Political Studies, 40(2), 207-227. https://doi.org/10.1111/1467-9477.12080

Anderson, T. W., \& Hsiao, C. (1982). Formulation and estimation of dynamic models using panel data. Journal of Econometrics, 18(1), 47-82.

Arellano, M., \& Bond, S. (1991). Some tests of specification for panel data: Monte Carlo evidence and an application to employment equations. The Review of Economic Studies, 58(2), 277-297.

Badescu, G., \& Uslaner, E. (2004). Social capital and the transition to democracy (Vol. 20). Routledge

Bargsted, M., Somma, N. M., \& Castillo, J. C. (2017). Political trust in Latin America. Edward Elgar Publishing.

Bellemare, M. F., Masaki, T., \& Pepinsky, T. B. (2017). Lagged explanatory variables and the estimation of causal effect. The Journal of Politics, 79(3), 949-963. https://doi.org/10.1086/690946

Bond, S. R. (2002). Dynamic panel data models: A guide to micro data methods and practice. Portuguese Economic Journal, 1(2), 141-162.

Brehm, J., \& Rahn, W. (1997). Individual-level evidence for the causes and consequences of social capital. American Journal of Political Science, 41, 999-1023.

Delhey, J., \& Newton, K. (2005). Predicting cross-national levels of social trust: Global pattern or Nordic exceptionalism? European Sociological Review, 21(4), 311-327. https://doi.org/10.1093/esr/jci022

Dellmuth, L. M., \& Tallberg, J. (2020). Why national and international legitimacy beliefs are linked: Social trust as an antecedent factor. The Review of International Organizations, 15(2), 311-337. https://doi.org/10.1007/s11558-018-9339-y

Dincer, O. C., \& Uslaner, E. M. (2010). Trust and growth. Public Choice, 142(1-2), 59. https://doi.org/ 10.1007/s11127-009-9473-4

Dinesen, P. T., \& Sønderskov, K. M. (2015). Ethnic diversity and social trust: Evidence from the microcontext. American Sociological Review, 80(3), 550-573. https://doi.org/10.1177/0003122415577989

Fairbrother, M., Sevä, I. J., \& Kulin, J. (2019). Political trust and the relationship between climate change beliefs and support for fossil fuel taxes: Evidence from a survey of 23 European countries. Global Environmental Change, 59, 102003. https://doi.org/10.1016/j.gloenvcha.2019.102003

Fukuyama, F. (1996). Trust: Human nature and the reconstitution of social order. Simon and Schuster. 
Gadermann, A. M., Guhn, M., \& Zumbo, B. D. (2012). Estimating ordinal reliability for Likert-type and ordinal item response data: A conceptual, empirical, and practical guide. Practical Assessment, Research, and Evaluation, 17(1), 3.

Glanville, J. L., \& Paxton, P. (2007). How do we learn to trust? A confirmatory tetrad analysis of the sources of generalized trust. Social Psychology Quarterly, 70(3), 230-242.

Helliwell, J., Huang, H., \& Wang, S. (2018). New evidence on trust and well-being. In Oxford Handbook of Social and Political Trust (pp. 409-446). Oxford University Press

Hetherington, M. J. (1998). The political relevance of political trust. American Political Science Review, 92, 791-808.

Holmberg, S., \& Rothstein, B. (2017). Trusting other people. Journal of Public Affairs, 17(1-2), e1645. https://doi.org/10.1002/pa.1645

Hyslop, D. R. (1999). State dependence, serial correlation and heterogeneity in intertemporal labor force participation of married women. Econometrica, 67(6), 1255-1294.

Kaase, M. (1999). Interpersonal trust, political trust and non-institutionalised political participation in Western Europe. West European Politics, 22(3), 1-21.

Kawachi, I. (2018). Trust and population health. In Oxford handbook of social and political trust (pp. 447-470). Oxford University Press.

Knack, S. (2002). Social Capital and the Quality of Government: Evidence from the States. American Journal of Political Science, 46(4), 772-785. https://doi.org/10.2307/3088433

Korpi, W., \& Palme, J. (1998). The paradox of redistribution and strategies of equality: Welfare state institutions, inequality, and poverty in the Western countries. American Sociological Review, 63, 661-687.

Lalot, F., Heering, M. S., Rullo, M., Travaglino, G. A., \& Abrams, D. (2020). The dangers of distrustful complacency: Low concern and low political trust combine to undermine compliance with governmental restrictions in the emerging Covid-19 pandemic. Group Processes \& Intergroup Relations. https://doi.org/10.1177/1368430220967986

Leszczensky, L., \& Wolbring, T. (2019). How to deal with reverse causality using panel data? Recommendations for researchers based on a simulation study. Sociological Methods \& Research. https:// doi.org/10.1177/0049124119882473

Levi, M., \& Stoker, L. (2000). Political trust and trustworthiness. Annual Review of Political Science, $3(1), 475-507$.

Lindstrom, M., \& Mohseni, M. (2009). Social capital, political trust and self-reported psychological health: A population-based study. Social Science \& Medicine, 68(3), 436-443. https://doi.org/10. 1016/j.socscimed.2008.11.004

Lipset, S. M., \& Schneider, W. (1983). The decline of confidence in American institutions. Political Science Quarterly, 98(3), 379-402.

Mattes, R., \& Moreno, A. (2018). Social and political trust in developing countries: Sub-Saharan Africa and Latin America. In Oxford Handbook of Social and Political Trust (pp. 357-382). Oxford University Press

Meijer, E., Spierdijk, L., \& Wansbeek, T. (2014). Measurement error in panel data. In B. Baltagi (Ed.), The Oxford Handbook of Panel Data (pp. 325-362). Oxford University Press.

Mishler, W., \& Rose, R. (2001). What are the origins of political trust? Testing institutional and cultural theories in post-communist societies. Comparative Political Studies, 34(1), 30-62.

Mondak, J. J., Hayes, M., \& Canache, D. (2017). Biological and psychological influences on political trust. Edward Elgar Publishing.

Moral-Benito, E., Allison, P., \& Williams, R. (2019). Dynamic panel data modelling using maximum likelihood: An alternative to Arellano-Bond. Applied Economics, 51(20), 2221-2232. https://doi. org/10.1080/00036846.2018.1540854

Nannestad, P. (2008). What have we learned about generalized trust, if anything? Annual Review of Political Science, 11, 413-436. https://doi.org/10.1146/annurev.polisci.11.060606.135412

Newton, K. (1997). Social capital and democracy. American Behavioral Scientist, 40(5), 575-586.

Newton, K., \& Zmerli, S. (2011). Three forms of trust and their association. European Political Science Review: EPSR, 3(2), 169. https://doi.org/10.1017/S1755773910000330

Newton, K., Stolle, D., \& Zmerli, S. (2018). Social and political trust. The Oxford Handbook of Social and Political Trust, 37, 961-976.

Newton, K., \& Norris, P. (2000) Confidence in public institutions. Disaffected Democracies. What's Troubling the Trilateral Countries, 52-73.

Offe, C. (1999). How can we trust our fellow citizens. Democracy and Trust, 52, 42-87. 
Putnam, R. D., Leonardi, R., \& Nanetti, R. Y. (1994). Making democracy work: Civic traditions in modern Italy. Princeton university press

Reed, W. R. (2015). On the practice of lagging variables to avoid simultaneity. Oxford Bulletin of Economics and Statistics, 77(6), 897-905. https://doi.org/10.1111/obes.12088

Rothstein, B., \& Stolle, D. (2008). The state and social capital: An institutional theory of generalized trust. Comparative Politics, 40(4), 441-459.

Rothstein, B., \& Uslaner, E. M. (2005). All for all: Equality, corruption, and social trust. World Pol., 58, 41.

Segovia, C. (2008). Political Trust in Latin America. University of Michigan (Unpublished Dissertation Thesis), Michigan

Seifert, N. (2018). Yet another case of Nordic exceptionalism? Extending existing evidence for a causal relationship between institutional and social trust to the Netherlands and Switzerland. Social Indicators Research, 136(2), 539-555. https://doi.org/10.1007/s11205-017-1564-x

Somma, N.M., Bargsted, M., Disi Pavlic, R., \& Medel, R. M. (2021). No water in the oasis: the Chilean Spring of 2019-2020. Social Movement Studies, 20(4), 495-502. https://doi.org/10.1080/14742837. 2020.1727737

Sønderskov, K. M. (2011). Does generalized social trust lead to associational membership? Unravelling a bowl of well-tossed spaghetti. European Sociological Review, 27(4), 419-434. https://doi.org/10. 1093/esr/jcq017

Sønderskov, K. M., \& Dinesen, P. T. (2016). Trusting the state, trusting each other? The effect of institutional trust on social trust. Political Behavior, 38(1), 179-202. https://doi.org/10.1007/ s11109-015-9322-8

Spadaro, G., Gangl, K., Van Prooijen, J.-W., Van Lange, P. A., \& Mosso, C. O. (2020). Enhancing feelings of security: How institutional trust promotes interpersonal trust. PLoS ONE, 15(9), e0237934. https://doi.org/10.1371/journal.pone.0237934

Torche, F. (2005). Unequal but fluid: Social mobility in Chile in comparative perspective. American Sociological Review, 70(3), 422-450.

United Nations Development Programme (UNDP). (2017). Desiguales. Orígenes, cambios y desafíos de la brecha social en Chile. UNDP; PNUD Santiago

United Nations Development Programme (UNDP). (2020). Diez años de auditoría a la democracia antes del estallido. In Programa de las Naciones Unidas para el Desarrollo, Santiago de Chile. United Nations Development Programme

Uslaner, E. M. (2000). Producing and consuming trust. Political Science Quarterly, 115(4), 569-590.

Uslaner, E. M. (2002). The moral foundations of trust. Cambridge University Press.

Vaisey, S., \& Miles, A. (2017). What you can-And can't-Do with three-wave panel data. Sociological Methods \& Research, 46(1), 44-67. https://doi.org/10.1177/0049124114547769

Valenzuela, E., \& Cousiño, C. (2000). Sociabilidad y Asociatividad un ensayo de sociología comparada (vol. 77, Verano 2007). Santiago de Chile: CEP

Van der Meer, T., \& Hakhverdian, A. (2017). Political trust as the evaluation of process and performance: A cross-national study of 42 European countries. Political Studies, 65(1), 81-102. https://doi.org/10. $1177 / 0032321715607514$

Wawro, G. (2002). Estimating dynamic panel data models in political science. Political Analysis, 10, $25-48$.

Whiteley, P. F. (2000). Economic growth and social capital. Political Studies, 48(3), 443-466.

Wooldridge, J. M. (2010). Econometric analysis of cross section and panel data. MIT press

Zak, P. J., \& Knack, S. (2001). Trust and growth. The Economic Journal, 111(470), 295-321. https://doi. org/10.1111/1468-0297.00609

Zmerli, S., \& Newton, K. (2008). Social trust and attitudes toward democracy. Public Opinion Quarterly, 72(4), 706-724. https://doi.org/10.1093/poq/nfn054

Zmerli, S. (2014). Political trust. In A. C. Michalos (Ed), Encyclopedia of Quality of Life and Well-Being Research. Springer Netherlands https://doi.org/10.1007/978-94-007-0753-5_2202

Publisher's Note Springer Nature remains neutral with regard to jurisdictional claims in published maps and institutional affiliations. 